\title{
UPSTAIRS/DOWNSTAIRS: INDIA, AUSTRALIA AND THE CHANGING DIVISION OF LABOUR IN 'OFFSHORE' ARCHITECTURAL PRODUCTION AND EDUCATION
}

\author{
PETER SCRIVER \\ School of Architecture, Landscape Architecture and Urban Design \\ University of Adelaide \\ Adelaide, SA 5005, Australia \\ peter.scriver@adelaide.edu.au
}

\section{PAOLO TOMBESI, BHARAT DAVE, AND BLAIR GARDINER}

Faculty of Architecture, Building and Planning

The University of Melbourne

Carlton, VIC 3010, Australia

\begin{abstract}
As with many other 'industries' routinely engaged in the digital production and exchange of information, global interconnectivity is driving a worldwide relocation of architectural design production and documentation facilities from higher-wage to lower-wage regions. With common professional and linguistic legacies from the colonial past, India is emerging as a key provider to Australia in this emerging market of offshore architectural services. Conversely, India is also one of Australia's most important emerging consumers of architectural education. Until recently, a 'foreign-returned' Indian architect with a degree from an overseas university could anticipate architectural employment in an 'upstairs' position of responsibility and prestige. Overseas qualifications typically entailed overseas work experience as well, and the enhanced professional judgement these implied to perform the higher order 'symbolic analysis' of a designer or project leader. It was the 'downstairs' staff of locally trained drafters and technicians who did the 'routine production' and were paid accordingly. With the rapidly increasing volume and sophistication of 'offshore' architectural work now being 'outsourced' to Indian firms, however, the old 'upstairs-downstairs' division of labour and expertise is no longer clear.

This paper interprets relevant findings from the Indian case study of a larger comparative study of the changing geography of architectural work. Here we question what an Australian architectural degree is actually worth, or should be, to an Indian graduate architect when locally trained architectural technicians based in Delhi, Mumbai, and even provincial Kanpur are routinely working on major projects around the Globe as remote digital collaborators with some of the largest architectural firms in the world.
\end{abstract}

Keywords: digital outsourcing, offshore architectural services, overseas education, India. 


\section{Introduction}

Recent advances in the digital production, representation and exchange of information are enabling dramatic changes in contemporary architectural design and practice. The evidence of this is already substantial. Most conspicuous is the extraordinary volume, scale and sophistication of architectural projects that are currently under construction in emerging new urban regions and economies of the Globe which, just a few years ago, were regarded as underdeveloped backwaters if they existed at all. Typically designed 'offshore', in many cases by leading corporate and avant-garde architectural firms, the timely production of these developments is enabled technically by the combination of computer-aided drafting and design (CADD) with the broadband interconnectivity of current internet-based information communication technology (ICT). Less conspicuously than the changing flows and concentrations of economic, political, and cultural capital that this new construction so spectacularly represents, these geography-collapsing ICT networks in which it is technically produced are enabling further exchanges of professional and technical knowledge. These flows are dramatically displacing and potentially completely restructuring labour and services in the architectural, engineering, and construction industries worldwide (Tombesi).

With the English language and other professional and institutional legacies of its British colonial past, India is already a key provider in the emerging market of offshore services for the architecture and construction industries of the UK, Canada and the USA, and increasingly Australia as well (Tombesi et al, "Routine Production"). It is no coincidence, perhaps, that India is also one of Australia's most important emerging consumers of architectural education. But what is the actual value of such an overseas architectural education, this paper asks, when even IT-savvy architectural technicians trained in undistinguished technical colleges in provincial India are in demand by fast-growing outsourcing agencies to work for some of the largest architectural and engineering firms in the world on projects ranging from skyscrapers in New York and Shanghai, to shopping malls in Poland, to suburban housing developments in Calgary and Melbourne?

To address this question critically, the operative premises of 'off-shoring' design production must also be cross-examined: How transferable are context-specific architectural knowledges across geographic distances and cultural divides? What types of knowledge and skills do effective distance collaborations of this kind depend on? Does this work require a mastery of increasingly complex building and information systems that extends beyond the purview of basic design production and technical support?

These are some of the key questions we are pursuing in a larger comparative study of Australia's prospects in this fast evolving new geography of 'globalised' architectural work (Scriver et al; Tombesi et al, "Evaluating Industrial Potential"; "Rules of Engagement"; Dave et al; Gardiner et al). The present paper focuses specifically on the division of labour and knowledge in the emerging IT-immersed sub-culture of 'outsourcers' within the contemporary Indian architectural profession.

\section{Upstairs downstairs}

As recently as the 1980s, the structure and operation of typical medium and large architectural firms in contemporary India could be characterised succinctly as an 'upstairs/downstairs' hierarchy. The 'upstairs' staff was the design professionals - principals, associates and graduate architects as well as student trainees of university-based or affiliated schools of architecture and design - who assumed responsibility for the higher-order intellectual labour of the office, as well as all design credit. Typically educated in English, the 'upstairs' staff readily engaged in the wider international debates of the profession.

The 'downstairs' staff was comprised of the clerical and technical support staff, and the draftsmen (and women) and clerks of works who produced the working drawings and liased with the construction industry and planning authorities. Larger firms often retained their own in-house engineers and quantity surveyors, with responsibility for technical coordination and the management of the documentation and construction phases of the work, but the rest of the 'downstairs' staff often had only vocational schooling. The language of work downstairs was the local vernacular.

The modernist ideologies that still dominate contemporary architectural education and practice privilege the 'atelier' or 'studio' as the ideal-type of architectural practice (Cuff 17-56). On the other hand, the division of professional knowledge and the work of 'symbolic analysis' from the procedural knowledge and labours of 'routine production' is a basic principle of industrial theory 
that many larger corporate practices, at least, have long exploited (Tombesi et al, "Routine Production"). However, the distinctive social and cultural segregation inherent in the division of labour typical in Indian architectural firms of the second half of the twentieth century also reflected the particular history of the Indian architectural profession with its origins under the former colonial system. To the limited extent that a 'modern' profession of architectural practitioners had been enabled to take root in India before the departure of the British in 1947, its organisational norms and practices remained very similar to those of the British Indian Public Works Department system (PWD). Within the engineer-dominated PWD system, in which many of the first generation of the nascent Indian architectural profession was trained, a small elite cadre of British architectural professionals had been assisted by a subordinate cadre of Indian draftsmen and clerks of works. With the departure of the British in 1947, the senior subordinate cadre rose to executive positions of professional authority within the technocratic framework of government service, but institutional inertia resisted deeper structural change.

In the post-independence era this inherited professional/technical division was reinforced by the promotion of general technical education under the 'modernisation' ethos of the new Indian Republic. With the emphasis on science and engineering as the primary tools of social and economic development, the comparatively esoteric concerns of 'Architecture' as an autonomous professional discipline were championed by the establishment of a handful of elite, selfconsciously 'professional' schools of architecture and planning. The avant-gardisme propagated by these schools and associated smaller design practices ostensibly contested the technicalservice model of practice propagated by the public works system and larger corporate firms. But this effectively reinforced a neo-colonial distinction between a professional class of elite architectural designers and a more humble and numerous class of mere technicians.

\section{Downstairs upstairs? An overview of Indian documentation service providers}

Over the past two decades, this conventional hierarchy has been radically challenged. Under neo-liberal economic policies that began to be introduced in the mid 1980s, India has reemerged as one of the most dynamic and innovative 'localities' in the global economy today. India's disproportionate stake in the intellectual capital that underpins the digital infrastructure of this global economy has played a key part in this paradigm shift (Heeks), and IT dependent industries such as Architecture, Engineering and Construction have experienced some of the most dynamic changes. The emergence of the outsourcing sub-industry is one of the most recent developments arising from the more fundamental emergence in this increasingly freewheeling, unregulated building scene, of a parallel formation of both qualified practitioners and para-professional providers of architectural services working outside the purview of the organised architectural profession. The defining characteristic of this less exclusive, more heterogeneous group is its commercial focus. Qualifications are valued from a strictly pragmatic rather than symbolic point of view, and the major currency in this regard is architectural data processing skills, not least facility with sophisticated CAD packages and other digital tools. (Tombesi et al, "Routine Production").

How then has this radical and irregular growth of a larger architectural 'industry' challenged the established norms and hierarchy of professional practice? Have the 'downstairs' technicians simply moved 'upstairs'? Our research on India's architectural outsourcing sector is revealing a more complex and ambiguous picture.

Supported by an ARC grant in 2005-2006, a research program was undertaken to better understand the complex interdependencies between technical, professional, and cultural knowledges in the production of architecture through remote collaboration. The core of the project is a series of controlled experiments in documentation collaboration between conventional Australian architectural offices and a range of service documentation providers, from local (Australian) drafting sub-contractors to global (offshore and/or internet-based) outsourcers (Dave et al). The exclusively digital parameters and evidence of these 'laboratory' experiments were complemented by field-work in India to investigate the internal organisation and practices, and the actual infrastructure and human-resources on which several of the participating offshore outsourcers in our study and their local competitors relied. Outlined below are some of the key findings of this ongoing research pertinent to our specific concern here with the structure and division of architectural work and knowledge in this fast evolving IT-driven subindustry.

Few if any architectural outsourcing firms existed in India a decade ago, but growth in this sector has been exponential in the last few years. Typical firms appear to fall into one of a small number of types. On one end of the scale are firms that openly and exclusively provide 
outsourcing services, employing hundreds of staff. On the other end are start-up operations with just 2-5 employees. Many firms have overseas 'front' offices with actual work being carried out in 'back' offices based in India. One variant of this is the 'captive unit' or wholly owned subsidiary of offshore firms. Another variant depends on free-agents, including Indian students enrolled in post-graduate degrees overseas, who broker connections between those seeking services in overseas markets and providers in India.

Services are provided on a 'project' basis, 'studio-mode' (dedicated staff working as long-term satellite staff of another office) or even 'person nodes' (in which one or more staff are 'attached' to overseas offices). Many firms also operate up to three shifts a day to respond to the volume of work and to align office hours with the different time zones of key client markets around the globe. The locations in India of the actual documentation production offices do not indicate any overarching patterns. Outsourcers are operating in big cities and small, and in every grade of accommodation from corporate office space to veritable sweat-shops.

Not only is the volume of 'offshore' architectural work produced in India increasing rapidly, but the sophistication as well. Technological capabilities and advantageous wage differentials are obvious drivers where, until recently, an experienced draftsperson in India earned approximately one tenth of the average starting salary for an architectural graduate in an Australian firm (Tombesi; APESMA). The typical scope of work begins with basic conversion to $\mathrm{CAD}$ of physical hand-drawn or drafted drawings, and the production and development of construction documentation. But 3D building information modelling (BIM) is rapidly becoming the new paradigm for the services offered. With the greater scope for coordination this technology enables, and the expert experience gained through successive jobs for repeat clients the majority of outsourcing firms openly aspire to play a more comprehensive role in the production of their client's projects. But, even where greater 'design' related scope of work is not the aim, it is still widely acknowledged that mere drafting technicians are not up to the job alone, as this requires a professional's sense of the complexity of criteria and details that need to be addressed and coordinated. Firms are therefore increasingly keen to recruit and retain more senior, professionally qualified staff, ideally with relevant overseas experience as well. There is also considerable awareness of the need for expert knowledge acquisition and development and through on-going staff training as a core priority of the business. India still works a six-day week, and Saturdays are the days on which employees are paid to learn more about the technologies they are using, and the technicalities and cultural differences of their current projects. In a fast changing industry, such staff development is also calculated to inspire loyalty through a sense of growth and maturation with the firm.

To summarise this very cursory description of relevant findings from our fieldwork, three key points can be emphasised: There is (1) ample evidence of rapid growth in both demand for and supply of offshore architectural services, in a range of different modalities; (2) evidence of rising expectations for greater scope of work and sophistication; and (3) a recognised need to proactively acquire a higher order of both technical and professional knowledge.

The latter point in particular is corroborated by the preliminary findings of our controlled collaboration experiments in which the paramount significance of the internal sub-cultural knowledges and practices particular to the specific firms engaged in such collaborative relationships has become very apparent (Gardiner et al.). If the outsourcers are to fully grasp the character and the details of the design work they are engaged to produce, and increasingly to assist in the detailed development of the designs as well, the commissioning firms need to be better attuned critically to their own formal and practical idiosyncrasies and how these may be understood and communicated. Thus, the possibility of developing and sustaining productive distance relationships does not depend on common norms and standards alone, but a common awareness of and engagement with complex contextual knowledges on both sides.

This key point has certainly not eluded the outsourcing industry and is the conscious aim of developing dedicated work teams as 'remote studios' for established offshore clients. As one of the industry leaders argues, "offshoring actually forces their junior staff [on both sides of the collaboration] to become technical and process experts, demanding both the knowledge of design and construction detailing, and also management skills as well, all of which benefit individual firms' employees" (Jansen). But beyond the particular vocational/technical and professional criteria of the work itself, access to additional contextual knowledge of the sociocultural kind is a probable further success factor in such distance collaboration. The phenomenal success of the largest India-based outsourcing firm is a case in point. Whilst a champion of the 'remote studio' model, the exceptional growth of this firm of $300+$ employees also appears to derive from intimate 'insider-knowledge' of the cultures of practice on both sides 
of the business relationship. The firm was founded in the late 1990s by a young expatriate American architect, now settled in Delhi. Following architectural studies at Yale and Cambridge, extensive post-professional studies in China and India as a Fullbright scholar, and a period of overseas work for one of the largest corporate firms in the USA, marriage to the daughter of an influential architectural educator on the Indian scene brought him back to Delhi to establish his own outsourcing firm. Together with a carefully coached team of senior managers recruited from the handful of elite Indian schools of architecture, the firm presents a powerful and persuasive ethos of professional command informed by an understanding of the values and practices sustained in the sub-cultures of elite architectural education in both India and the American Ivey League.

\section{Conclusion}

To conclude, let us return then to the question of architectural education latent in the preceding observation, and what we suggest are some of the possible implications of these 'offshore' developments in technologically globalised architectural production for architectural learning today.

In a salient essay, the celebrated Indian architect, Charles Correa (445-56), invokes a wellknown parable from Indian mythology to serve an argument about architectural education. The story concerns an untouchable slave boy, Ekalavya, who so passionately venerates the mastery of a great Brahmin archer, from the necessary distance prescribed by his lowly social station, that he virtually masters the art himself. But the boy's cruel fate for this miraculous conceit is to sever his thumb so he can never draw a bow again. Correa's point is that architecture can almost certainly be 'learned' mimetically, whether or not it can be 'taught' effectively. And, learning about the craft and intrinsic cohesion of the discipline is perhaps no more felicitously gained, he argues, than through intensive immersion in the work of other accomplished designers - not least through the devoted, even slavish copying of the 'masterclass' studio (or, we might add, the 'remote studio' services typically offered by offshore documentation firms). But to become a mature and original designer in one's own right, Correa counters, the delusion of mastery through mimicry must necessarily be challenged, in any good architectural education, with a healthy balance of critical 'distancing'.

Written in the mid 1990s for a collective volume on 'the education of the architect' put together by faculty and affiliates of MIT (where Correa teaches and had, himself, been an international graduate student in the early 1950s), Correa's essay articulated the distancing function of the theoretically and critically rich curricula that such elite schools were celebrated for. This was the necessary counterpoint to the charismatic immersion of the master-class studios that they were equally well-placed to provide and which students with the requisite brilliance (or finances) flocked from every corner of the planet to experience. But Correa was also certainly conscious of passionate debates at the time about MIT's radical commitment under its new ex-pat Australian Dean of Architecture, Bill Mitchell, to total digital immersion in the new paradigm of the 'paperless studio'. One could therefore read Correa's conventional wisdom about complementarity and balance in the substance of an education, in a slightly different light. The seduction of virtual mastery through digital technique had all the more to be countered by critical inquiry, humility and introspection about the just balance between the visual and the verbal in architectural learning; the technical and the ethical.

Over a decade later, the digital tools and templates we use to craft the global architecture of today are as ubiquitous as the virtual realities they are prone to produce. The typical Indian or Chinese international student arrives to study architecture at an Australasian university with IT user skills that are equivalent or often superior to those of their Australasian educated classmates. Surely, then, it is the 'distancing' - geographic, cultural and above all 'critical' - that such a student experiences when they actually travel overseas in which the real pedagogical value of that investment resides.

In the competitive scramble for international student recruitment and retention, Australasian schools of architecture should take note: it is not generic vocational training that is wanted. As Adrian Snodgrass (35-43) has cautioned, this assumption is not only patently neo-colonial, but naïve. What we need to initiate in our increasingly international studios and classrooms is a dialogue between future 'collaborators' in an emerging global exchange of expert services and knowledge; between different professional sub-cultures of critical practitioners who will need to be equally reflexive about their own practices and locality as they are acquisitive (and hopefully inquisitive too) about the opportunities of the global. 


\section{References}

APESMA, Architects Remuneration Survey Report 1998-99. Melbourne: Association of Professional Engineers Scientist and Managers Australia, Architects Branch, 1998.

Correa, C. "Learning from Ekalavya." In Martha Pollak, ed. The Education of the Architect: Historiography, Urbanism, and the Growth of Architectural Knowledge. Cambridge, Mass: MIT Press, 1997, 445-456.

Cuff, D. Architecture: The Story of Practice. Cambridge, Mass: MIT Press, 1992.

Dave, B., Tombesi, P., Gardiner, B., and Scriver, P. "Digital outsourcing in architecture: Sifting through promises, problems and myths." INCITE-ITCSED 2006, IT Solutions of the Design \& Management of Infrastructure Construction Projects, Construction Industry Development Council \& Glasgow Caledonian University, New Delhi (2006): 257-270.

Gardiner, B., Tombesi, P., Dave, B., and Scriver, P. "Understanding qualitative drivers in distance collaborations for architectural services." Digital Architecture and Construction 2006. Southampton, UK: WIT Press, 2006, 155-166.

Heeks, R. India's Software Industry: State Policy, Liberalisation and Industrial Development. New Delhi: Sage Publications, 1996.

Jansen, M. "Offshore Outsourcing." Unpublished paper, September 2006.

Scriver, P., Tombesi, P., Dave, B., and Gardiner, B., "Globality, Locality and Freedom in the India of 'Satellier'." Panorama to Paradise: Scopic Regimes in Architectural and Urban History and Theory, Proceedings of the $24^{\text {th }}$ Annual Conference of the Society of Architectural Historians, Australia and New Zealand (SAHANZ), Adelaide, Sept 21-24, 2007.

Snodgrass, A. "Asian Studies and the Fusion of Horizons." Gadamer, Action and Reason, conference proceedings, Sydney: University of Sydney, 1991, 35-42.

Tombesi, P. "A true south for design? The new international division of labour in architecture." Architectural Research Quarterly, 5/2 (2001): 171-180.

Tombesi, P., Dave, B., and Scriver, P. "Routine Production or Symbolic Analysis? India and the Globalization of Architectural Services." The Journal of Architecture, 8/1 (Spring 2003): 63-94

Tombesi, P., Dave, B., Gardiner, B., and Scriver, P. "Evaluating the Industrial Potential of Digital Outsourcing in Architecture: Methodological Challenges and Choices." In S. Emmitt and M. Prins, eds, Designing Value: New Directions in Architectural Management, Proceedings of the CIB W096 Architectural Management, Publication no. 307, Technical University of Denmark, Lyngby Denmark, 2-4 (November, 2005): 441-450.

Tombesi, P., Dave, B., Gardiner, B., and Scriver, P. "Rules of engagement: Testing the attributes of distant professional marriages." Journal of Architectural Engineering and Design Management 4/2 (2007): in press. 